\section{Okolo AA Omoyibo E Chimah UO}

DOI:http://dx.doi.org/10.4314/njp.v42i4.10

Accepted: 10th August 2015

Okolo AA ( $\boldsymbol{\square})$

Department of Child Health, University of Benin Teaching Hospital Benin City, Nigeria.

Email: angelneneo@yahoo.com

Omoyibo E, Chimah UO

Department of Pediatrics, Federal Medical Centre Asaba Nigeria.

\title{
Breastfeeding practices and growth
}

\begin{abstract}
Background: Breastfeeding is vital for the growth and development of infants and young children. Early initiation within the half hour of birth fosters optimal breastfeeding practice, promotes growth and development. Objective: To evaluate breastfeeding practices and the growth of infants.

Method: This was a crosssectional survey at three immunisation clinics in Asaba metropolis of Delta state. Using a structured questionnaire, we assessed breastfeeding practice of attendees and the growth of babies and documented information on the socio demographic characteristics, breastfeeding practices, previous weights of infants' and their Anthropometric measurements.

Results: There were 97 motherinfant/ pairs. 49 males, 48 females; giving a male to female ratio of $1: 1$. 20.6\% were neonates, $74.2 \%$ were less than 6 months while $25.8 \%$ were older. About 50\% of the mothers initiated breastfeeding within an hour
\end{abstract}

of delivery, $25 \%$ of mothers gave pre-lacteal feeds. $49.5 \%$ of babies were optimally breastfed; of these, $68.7 \%$ mothers had initiated breastfeeding within an hour of birth $(p=0.001)$. Underweight and stunting was only seen among babies of mothers who did not practice optimal breastfeeding.

It was observed that babies' weights were not documented routinely in the road to health chart of the immunization cards after the measurements were taken. This was a missed opportunity for counselling and health promotion.

Conclusion: Early initiation of breastfeeding increases the probability of optimal breastfeeding practice and prevents infant malnutrition. Even though growth was assessed, the information was not utilized for feed back to the mothers at the well-baby clinics, growth monitoring and promotion was not supported at the well-baby clinics in the health centres.

Key words: Breastfeeding Initiation; Growth.

\section{Introduction}

Breastfeeding is the gold standard of nutrition for infant and young child survival and development. Mothers' breastfeeding babies of the same age seem to have about the same composition of breast milk provided the mother is not severely under nourished ${ }^{1}$. Severe maternal malnutrition is not common except in situations of war, famine, natural disasters such as earth quake, tsunami etc. Milk remains the primary source of nutrition for new-borns before they are able to eat and digest other foods; older infants and toddlers may continue to be breastfed, either exclusively or in combination with other foods ${ }^{1}$. Breastfeeding (BF) practice is said to be optimal when breastfeeding has been initiated within the hour of birth, thereafter exclusive breastfeeding is practiced in the first six months of life, thereafter, breastfeeding is continued thereafter up till age two years whilst suitable complementary foods are added. Breast milk contains appropriate amounts of carbohydrate, prtein, and fat, and it also provides vitamins, minerals, digestive enzymes, and hormones to the baby ${ }^{1,2}$. Its benefits for infant nutrition, growth and development, reduced morbidity and mortality, and prevention of long -term chronic diseases is widely recognized and cannot be over emphasised ${ }^{1,3,4}$. Black and co-workers in 2008, reported that suboptimum breastfeeding, especially nonexclusive breastfeeding in the first 6 months of life, results in 1.4 million deaths and $10 \%$ of the disease burden in children younger than 5 years in low-income and middle-income countries like Nigeria ${ }^{5}$.

Malnutrition is a major underlying factor causing deaths among children ${ }^{6}$. As much as fifty six percent of deaths among children in West African sub region could be averted if children were not malnourished ${ }^{6}$. Preventing malnutrition would be better achieved by getting it right from the outset when a child is born with the practice of optimal breastfeeding and this would help to increase the number of children surviving beyond their 5th birth- 
day.

According to UNICEF's state of the world's children $2014,{ }^{7}$ only $15 \%$ of children aged less than 6 months are exclusively breastfed in Nigeria which is far below the $90 \%$ recommendation by WHO/UNICEF for children less than 6 months in developing countries; ${ }^{8}$ while only $35 \%$ are still breastfeeding at the age of $2^{7}$. This contributes to the high malnutrition rates observed among children in Nigeria where $24 \%, 36 \%$ and $10 \%$ of under five years old children are underweight, stunted and wasted respectively ${ }^{7}$.

Several programmes aimed at reducing neonatal and infant mortalities have been designed to identify those interventions that could have great potential in reducing mortality. The Bellagio child survival study group identified breastfeeding as the lead intervention to improve child health and survival; with estimates that optimal breastfeeding could prevent $13 \%$ of all deaths of children below 5 years ${ }^{8}$.

It is a well-established fact that babies who initiate breastfeeding within one hour of life are more likely to have longer chance of exclusive breastfeeding and to be optimally breastfed. This will improve the nutritional status of the infant, promote optimal growth and development and in the long run reduce morbidity and mortality. Hence, WHO and other organizations recommend delaying for at least the first hour, routine newborn care procedures that separate mother from her baby such as bathing and weighing ${ }^{9,10}$. This will allow the mother and her new-born baby uninterrupted skin-to-skin contact until the first breast feed ${ }^{10}$. Delay in initiation of breastfeeding is associated with substantial morbidity and mortality ${ }^{5,6}$. Evidence abounds that early initiation of breastfeeding and exclusive breastfeeding are both linked with substantially lower neonatal mortality, ${ }^{6,11,12}$ hence mothers are encouraged to adopt this practice. Globally, over one million new-born infants could be saved each year by initiating breastfeeding within the first hour of life ${ }^{11}$.

Hence, this survey is being carried out to evaluate the breastfeeding practice amongst mothers and to relate it to the growth of their healthy infant who has not suffered from frequent morbidities as diarrhoea or acute respiratory tract infections. Mothers who initiate breastfeeding within the first hour of delivery of their babies are more likely to breastfeed their babies exclusively as recommended and have healthier babies with better nutritional status.

Aim: To assess breastfeeding practices and the growth of infants of mothers attending immunization clinics at three immunization centres in Oshimili South LGA of Delta State.

Specific

- To evaluate the time of initiation of breastfeeding and its relationship to optimal breastfeeding.

- To see if the time of initiation of breastfeeding significantly affects the weight and length of the infants.

\section{Methodology}

This was a hospital - based descriptive study on the breastfeeding practice by mothers of healthy breastfed babies and the growth of their babies. The study was carried out in October 2014 on a cross section of mothers who brought their babies for immunization at the primary health care (PHC) clinics, Secondary level hospital and tertiary level hospital at Umuagu PHC, St Josephs' Catholic Hospital and the Immunisation clinics of the Federal Medical Centre (FMC) Asaba.

\section{Ethical consideration}

Ethical approval was obtained from the tertiary level hospital Ethical Committee and informed consent of the respondents was obtained.

\section{Subjects}

All mothers who brought their babies for immunization during the period of the study at the various immunization centres at Umuagu PHC, St Joseph's Hospital and FMC Asaba and gave consent for the study were recruited and the questionnaire was administered to them. Their identities were coded.

\section{Data collection}

Information on the bio data, ante natal, perinatal and breastfeeding pattern of the babies was obtained from the mother/ care giver who brought the baby for immunization using a structured questionnaire. The SECA Basinet Infant weighing Scale was the standard scale utilised at these centres. The current weight, length and head circumference of the babies were taken.

Babies were weighed by means of the SECA infant weighing scale with the capacity of measuring the weight from 0 to $20 \mathrm{~kg}$ in $100 \mathrm{~g}$ dimensions. The scale was standardized using a $5 \mathrm{~kg}$ standard weight after every 20 measurements were taken. All babies were weighed naked.

Supine length was taken with the aid of an improvised infant meter made by the attachment of a non-expansible steel measuring tape to a Tee Square with a moveable frame attached at the long arm of the Tee square. Babies were placed supine with their head touching the short arm of the Tee square which was marked as $0 \mathrm{~cm}$, feet were held together and stretched on the long arm of the Tee square to avoid any flexion at the hip/knee joint. The moveable frame was adjusted on a horizontal frame to touch the feet of the babies on the perpendicular plane and the length was read from the steel tape. Length was measured to the nearest $0.5 \mathrm{~cm}$.

Head circumference was measured with the aid of a nonexpansible measuring tape as the maximum circumference of the head with the tape passing above the supraorbital ridges and over the maximum occipital protuberance. Head circumference was measured to the nearest $0.1 \mathrm{~cm}$.

Optimal breastfeeding practice in this context involves 
early initiation of breastfeeding, exclusive breastfeeding for the first six months of life, thereafter, with addition of complementary foods breastfeeding continues to $2 \mathrm{yrs}$ of age. Optimal breastfeeding practice was based on what is expected at the current age of the child.

Overweight means weight for age greater than the $97^{\text {th }}$ centile using the WHO chart.

Underweight means weight for age less than the $3^{\text {rd }}$ centile using the WHO chart.

Normal weight means weight for age between the $3^{\text {rd }}$ and $97^{\text {th }}$ centile using the WHO chart.

Stunting means height for age less than the $3^{\text {rd }}$ centile using the WHO chart.

Normal height means height for age between the $3^{\text {rd }}$ and $97^{\text {th }}$ centile using the WHO chart.

Gestational age, as obtained historically, from mothers, was taken into cognisance when assessing the weight for age and height for age.

\section{Data analysis}

The data collected were entered into a computer IBM/ SPSS package which was applied for analysis and results. Results are presented using frequency tables and charts. Statistical significance was set at a "p"-value < 0.05 .

\section{Results}

A total of 97 mother to infant/toddler pairs were recruited for the study. 48 were males and 47 werefemales with a ratio of approximately $1: 1$. At the time of the study, $20(20.6 \%)$ of the babies were neonates, 72 (74.2\%) were less than 6 months, while only $1(1 \%)$ was a year and above. The age of the mothers ranged from 20 to 46years with a mean age of $30.5 \mathrm{yrs} \pm 5.1 \mathrm{yrs}$. More than half (59.8\%) of the mothers were multiparous and $60.8 \%$ had up to tertiary level of education. Antenatal clinic attendance was $97.9 \%$.

Fig 1: Pie chart showing educational status of mothers

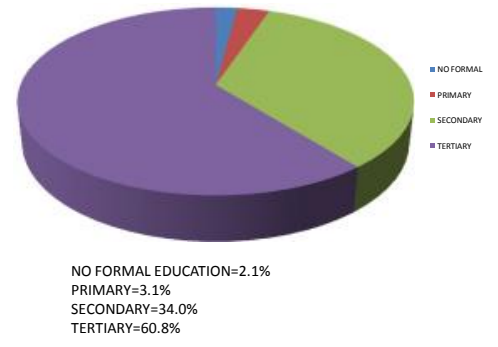

Eighty eight percent $(88 \%)$ of the study population were from either high or middle socioeconomic class.

About half of the mothers (49.5\%) initiated breastfeeding within an hour of delivery, while $4 \%$ commenced breastfeeding on the $3^{\text {rd }}$ day of life; and all were on admission. $75 \%$ of the admission was due to prematurity while the reason for admitting the last baby was not known to the mother.
Fig 2: Bar chart showing the time of initiation of breastfeeding.

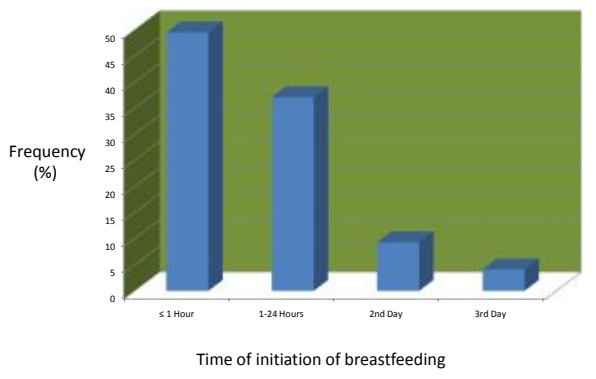

Twenty five percent of mothers gave prelacteal feeds and the reason for its use was attributed to lack of breast milk at the time. Only 1 attributed it to the effect of anaesthesia following a caesarean delivery. As at the time of the study, $49.5 \%$ of the babies were been optimally breastfed with a higher percentage (68.8\%) among those who initiated breast feeding within the first hour of life. Optimal breastfeeding practice was significantly associated with the time of initiation of breastfeeding. Table 1

\begin{tabular}{llll}
\hline Parametres & $\begin{array}{l}\text { OBF Fre- } \\
\text { quency (\%) }\end{array}$ & $\begin{array}{l}\text { Non-OBF } \\
\text { Frequency }(\%)\end{array}$ & $\begin{array}{l}\text { Total } \\
\text { Frequency } \\
(\%)\end{array}$ \\
\hline Within 1hour & $33(68.8)$ & $15(31.2)$ & $48(100.0)$ \\
1 -24hours & $13(36.1)$ & $23(63.9)$ & $36(100.0)$ \\
$2^{\text {nd }}$ Day & $1(11.1)$ & $8(88.9)$ & $9(100.0)$ \\
$3^{\text {rd }}$ Day & $1(25.0)$ & $3(75.0)$ & $4(100.0)$ \\
Total & $48(49.5)$ & $49(50.5)$ & $97(100.0)$ \\
\hline & & & \\
p $2=15.95$ & & &
\end{tabular}

None of the babies put to breast within the first 24 hours of life was underweight however six of these babies (7.1\%) were overweight. The point in time weight of the babies was significantly associated with the time of initiation of breastfeeding.

\begin{tabular}{lllll}
\hline Parametre & $\begin{array}{l}\text { Under- } \\
\text { weight } \\
\text { frequency } \\
(\%)\end{array}$ & $\begin{array}{l}\text { Normal } \\
\text { weight } \\
\text { frequency } \\
(\%)\end{array}$ & $\begin{array}{l}\text { Over weight } \\
\text { frequency } \\
(\%)\end{array}$ & $\begin{array}{l}\text { Total } \\
\text { Frequency } \\
(\%)\end{array}$ \\
\hline Within 1 hour & $0(0.0)$ & $44(91.7)$ & $4(8.3)$ & $48(100.0)$ \\
1 -24hours & $0(0.0)$ & $34(94.4)$ & $2(5.6)$ & $36(100.0)$ \\
$2^{\text {nd }}$ Day & $1(11.1)$ & $8(88.9)$ & $0(0.0)$ & $9(100.0)$ \\
$3^{\text {rd } D a y}$ & $1(25.0)$ & $3(75.0)$ & $9(0.0)$ & $4(100.0)$ \\
Total & $2(2.0)$ & $89(91.8)$ & $6(6.2)$ & $97(100.0)$ \\
\hline
\end{tabular}

$\chi^{2}=17.108$

$\mathrm{p}$ value $=0.008$

Stunting was only noticed among babies of mothers who initiated breastfeeding on the $3^{\text {rd }}$ day of life and all of them were already on mixed feeding. There was a significant association between the time to initiate breastfeeding and babies length.

\begin{tabular}{llll}
\hline Parametre & $\begin{array}{l}\text { Stunted } \\
\text { frequency } \\
(\%)\end{array}$ & $\begin{array}{l}\text { Normal } \\
\text { Frequency } \\
(\%)\end{array}$ & $\begin{array}{l}\text { Total } \\
\text { Frequency } \\
(\%)\end{array}$ \\
\hline Within 1 hour & $0(0.0)$ & $48(100.0)$ & $48(100.0)$ \\
1 -24hours & $0(0.0)$ & $36(100.0)$ & $36(100.0)$ \\
$2^{\text {nd }}$ Day & $1(11.1)$ & $9(100.0)$ & $9(100.0)$ \\
$3^{\text {rd } D a y ~}$ & $1(25.0)$ & $1(25.0)$ & $4(100.0)$ \\
Total & $2(2.0)$ & $94(96.9)$ & $97(100.0)$ \\
\hline
\end{tabular}

$x^{2}=74.229$

$\mathrm{p}$ value $<0.001$ 


\section{Discussion}

This study set out to evaluate the pattern of breastfeeding and the growth of the infants. It was how ever observed that although the weights of these infants were measured at each immunisation clinic visit these weights were not documented on the road to health chart and so the counselling aspect of growth monitoring and promotion with mothers was not implemented. The babies were however observed in the course of the study to be growing well. The absence of counselling of the mothers did not support the need for implementation of growth monitoring and promotion and might have implications for the future attendance at growth monitoring and immunisation clinics. Also this situation creates opportunities for none support of nutritional advice that addresses the individual health and nutrition needs of the index child at the Well-baby clinics where the focus should be disease prevention in all its ramifications. Well -baby clinics are supposed to meet the individual child health related needs, through immunisation, breastfeeding promotion and nutritional education and counselling to meet the individual infant's needs. Lack of growth monitoring and promotion is a missed opportunity for correct implementation of the complete well -baby clinic package.

Antenatal clinic attendance was quite high (97.9\%), this could be attributed to the fact that it was a hospitalbased study and so the respondents would have been mainly those that seek orthodox care.

Majority of the mothers were less than 40 years and multiparous, this implies that breastfeeding education should be focused on young women and adolescents so as to foster the culture of breastfeeding in them.

The Baby Friendly Hospital Initiative (BFHI) was designed to promote early initiation of breastfeeding, preferably immediately after birth. This study observed that $48(49.5 \%)$ of mothers initiated breastfeeding within an hour after birth. This is high compared to our national average of $23 \%^{7}$ and what was found in Ilesha and a rural community in Sokoto where only $8 \%$ of mothers initiated breastfeeding early ${ }^{13,14}$. This could be attributed to the fact that our study was hospital- based, in an urban center and also majority of mothers $(94.8 \%)$ had up to secondary level of education and so could appreciate what was being discussed during the Ante Natal Clinic (ANC) visit.

The EBF rate and optimal breastfeeding practice (49.5\%) observed among the study population was high compared to the national average of $15 \%^{7}$. This may be due to the fact that the ANC breastfeeding education was optimal amongst these mothers and enabled better understanding of the relevance of breastfeeding as was noticed by Okafor and colleagues ${ }^{15}$ in Lagos while studying the breastfeeding practices of mothers of young children. Majority of mothers who practiced optimal breastfeeding $(68.8 \%)$ initiated breastfeeding within an hour and these had a significant association. This is in keeping with the theory that early initiation of breastfeeding increases the likelihood of optimal breastfeeding practice $^{16}$.

The presence of large numbers of multiparous women in this study might have influenced early initiation of breastfeeding as establishment of lactation in mothers improves with increasing parity and experience.

Better nutrition enhances growth and development. In this study, only a few babies were underweight or stunted and these group of babies were among those who commenced breastfeeding more than 24 hours after birth. Although breastfeeding alone is not the only contributor to growth, our finding that early initiation of breastfeeding increases the likelihood of optimal breastfeeding might support the principle that optimally breastfed babies may have less frequency of illness in the first 6 months of life as EBF is known to reduce the frequency of diarrhea episodes and thus promote optimal growth $^{17}$. About $7 \%$ of babies who initiated breastfeeding within 24 hours were in the overweight category. However, exclusive breastfeeding has been found to reduce the risk of developing obesity ${ }^{1,18}$ and our study did not exclude other confounding variables like high birth weight which is a risk factor for being overweight. Generally, the better nutritional status observed among the babies might have resulted from the fact that $95 \%$ of mothers had relatively enhanced social and environmental circumstances that better supported child caring practices.

The absence of previous weight records in the- road tohealth Chart is to be noted as this illustrates the lack of adequate growth monitoring and promotion activities at these immunization centers where this simple procedure helps in the better counseling session of mothers who utilize these clinics. Such Growth monitoring and promotional activities should be seen as the opportunity for counselling of mothers on child care practices that should enhance the quality of care offered to the mothers.

\section{Conclusion}

The practice of early initiation of $\mathrm{BF}$ as an important entry point in this study is associated with the probability of optimal breastfeeding (OBF) practice in the population studied. OBF practice will help to prevent infant malnutrition and thereby contribute to reduction of morbidity and mortality in children less than five years. Malnutrition is a major cause of morbidity and mortality in children under five years of age; therefore, early initiation of breastfeeding should be promoted.

\section{Recommendations}

1. Antenatal breastfeeding education should refocus the importance of early initiation of breastfeeding as soon as the babies are born.

2. Growth monitoring and promotion should be implemented correctly at infant welfare clinics.

3. Breastfeeding education should target adolescents and the young to foster this culture. 


\section{Limitation of the study}

Anthropometric measurements of babies were not documented in the road to health chart during immunization in all but one of the babies and so the growth pattern for each infant

could not be assessed.

The study did not evaluate for the relationships of other morbidities that would influence growth of infants.
Conflict of Interest: None

Funding: None

\section{Acknowledgements}

The Authors gratefully acknowledge the care and support provided by the health Staff to the clinic attendees

\section{References}

1. Egbuonu I, Ojukwu JU. Infant feeding. In: Azubuike JC, Nkangieneme KEO, editors. Paediatrics and Child Health in a tropical region. $2^{\text {nd }}$ ed. University of Port Harcourt press; 2007. p. 226-37.

2. Ann P. Constituents of human milk. Food and nutrition bulletin.1996;vol 17(4). http:// archive.unu.edu/unupress/ food/8F174e/8F174E05.htm

3. Jana AK. Interventions for promoting the initiation of breastfeeding: RHL commentary (last revised: 2 March 2009). The WHO Reproductive Health Library; Geneva: World Health Organization.

4. Bahl R, Frost C, Kirkwood BR, Edmond K, Martines J, Bhandari $\mathrm{N}$ et al. Infant feeding patterns and risk of death and hospitalisation in the first half of infancy. : multicenter cohort study. Bull World Health Organ 2005, 83(6):418426.

5. Black R, Allan LH, Bhutta ZA, Caulfield LE, de Onis M, Ezzati M, et al. The Maternal and Child Under nutrition Study Group: Maternal and child under nutrition: global and regional exposures and health consequences. Lancet 2008;371:243-260.

6. Edmond KM, Zandoh C, Quigley MA, Amenga-Etego S, OwusuAgyei S, Kirkwood BR. Delayed breastfeeding initiation increases risk of neonatal mortality. Pediatrics. 2006;117(3):380-386.
7. UNICEF. State of the world's children 2014.

8. Jones G, Steketee R, Black R, Bhutta Z, Morris S. The Bellagio child survival study group. How many child deaths can we prevent this year? Lancet 2003; 362(19):65 $-71$

9. World Health Organization. Thermal Protection of the Newborn: A Practical Guide. Geneva: WHO; 1997.

10. Chaparro CM, Lutter C. Beyond Survival: Integrated Delivery Care Practices for Long-term Maternal and Infant Nutrition, Health and Development. Washington DC: Pan American Health Organization; 2007.

11. Mullany LC, Katz J, Li YM, Khatry SK, LeClerq SC, Darmstadt GL, et al. Breast-feeding patterns, time to initiation, and mortality risk among newborns in southern Nepal. J Nutr. 2008;138(3):599603.

12. Debes AK, Kohli A, Walker N, Edmond K, Mullany LC. Time to initiation of breastfeeding and neonatal mortality and morbidity: a systematic review. BMC Public Health. 2013;13(3):519.

13. Kuti O, Adeyemi AB, Owolabi AT. Breastfeeding pattern and onset of menstruation among Yoruba mothers of South-west Nigeria. Eur J Contracept reprod Health Care. 2007; 12:335-9.
14. Oche MO, Umar AS. Breastfeeding practices of mothers in a rural community of Sokoto, Nigeria. Niger Postgrad Med J. 2008;15:101-4.

15. Okafor IP, Olatona FA, Olufemi OA. Breastfeeding practices of mothers of young children in Lagos, Nigeria. Niger J Paed 2014; 41(1):43-47.

16. WHO. Early initiation of breastfeeding (internet).2005. Website assessed Oct 2014. Available at http://www.who.int/elena/titles/ early_breastfeeding/en/

17. Ahiadeke C. Breast-feeding, diarrhoea and sanitation as components of infant and child health: a study of large scale survey data from Ghana and Nigeria. J Biosoc Sci. Jan 2000;32(1):47-61.

18. Lausten-Thomsen U, Bille D S, Nässlund I, Folskov L, Larsen T, Holm J C. "Neonatal anthropometrics and correlation to childhood obesity - data from the Danish Children's Obesity Clinic". European J Pediatr. 2013;172 (6): 747 751. 